\title{
Handgrip strength and hand dimensions in high-level inter-university judoists
}

\author{
Authors' Contribution: \\ A Study Design \\ B Data Collection \\ C Statistical Analysis \\ D Manuscript Preparation \\ E Funds Collection
}

\author{
Juan M. Cortell-Tormo ${ }^{1 A B C D E}$, Jose A Perez-Turpin ${ }^{1 A B C D E}$, Ángel G. Lucas-Cuevas ${ }^{2 C D E}$, \\ Pedro Perez-Soriano ${ }^{2 \mathrm{BDE}}$, Salvador Llana-Belloch ${ }^{2 \mathrm{BDE}}$, Maria Jose Martinez-Patiño ${ }^{3 \mathrm{BDE}}$ \\ ${ }^{1}$ Department of general and Specific Didactics, Faculty of Education, University of Alicante, Alicante, Spain \\ ${ }^{2}$ Department of Sport and Physical Education, University of Valencia, Valencia, Spain \\ ${ }^{3}$ Faculty of Educational Sciences and Sports, University of Vigo, Vigo, Spain
}

Source of support: Departmental sources

Received: 9 January 2012; Accepted: 17 Dedember 2012; Published online: 21 February 2013

ICID: 883826
Background \& Study Aim:

Material \& Methods: Fifty four judokas aged 19-25 years participants of the Inter-University Championship of Spain 2009 took part in this study. Body height and body mass were measured and body mass index was calculated as general anthropometric parameters. Three groups of hand specific parameters were measured: finger spans, finger lengths and hand perimeters. The handgrip strength was measured by digital dynamometer in both hands.

Results: The general and some hand-specific (finger lengths, hand perimeters) measurements were significantly different among the weight groups $(\mathrm{p}<0.05)$ and positively correlated with handgrip strength for the whole group. However, only a few measurements - IFL,MFL,P4,P5 - were positively correlated among weight groups. Poor correlations were found between hand-specific variables - TL,IFL,MFL,P4 - and sport achievement. Only P3 was highly correlated with sport achievement and together with FSI explained $44.4 \%$ of its variance.

\begin{abstract}
Conclusions: The results indicate that the handgrip strength is mostly dependent on the basic (body height) and hand-specific (IFL, MFL, and P4) anthropometric parameters in judokas. Sport achievement was related to hand perimeter (P3), but its variability was weakly explained and thus hand-specific measurements may not be good predictors for judo performance.
\end{abstract}

Key words: $\quad$ hand dynamometry $\bullet$ Judo $\bullet$ handgrip $\bullet$ hand anthropometrics $\bullet$ performance
Juan M. Cortell-Tormo, Department of General and Specific Didactics, Faculty of Education, University of Alicante, Spain; e-mail: jm.cortell@ua.es
Hand-grip strength - the ability to exert force while grasping an apparatus with one hand.

Judo - literally means "the way of gentleness". Nowadays is an Olympic sport involving throwing grappling, strangles, and elbow-joint lock techniques.

\section{BACKGROUND}

Handgrip strength is an important measure in several sport disciplines $[1,2]$, in fact, many sports require a sustained level of hand prehensile force to maximize control and performance $[2,3]$ as well as to reduce the possibility of injuries [4].
Strength and endurance are potential predictors of judo performance [5-7]. Judo athletes require a combination of strength and endurance during grip combat to control the distance between them and their opponent $[8,9]$. The ability to rapidly mobilize a strong grip and pull or push the opponent is a highly valued attribute in judo athletes [10]. However, Franchini et al. [10] did 
Table 1. Sport achievement by weight category.

\begin{tabular}{cccc}
\hline Weight category & Achievement & Frequency & Percentage \\
\hline \multirow{3}{*}{$50-66$} & $1-3$ & 2 & 13.3 \\
\cline { 2 - 4 } & $4-6$ & 4 & 26.7 \\
\cline { 2 - 4 } & $7-10$ & 6 & 40.0 \\
\hline \multirow{2}{*}{$67-81$} & +11 & 3 & 20.0 \\
\cline { 2 - 4 } & $1-3$ & 2 & 9.5 \\
\hline & $4-6$ & 6 & 28.6 \\
\hline & $7-10$ & 8 & 38.1 \\
\hline & +11 & 5 & 23.8 \\
\hline & $1-3$ & 5 & 27.8 \\
\hline & $4-6$ & 6 & 33.3 \\
\hline & $7-10$ & 7 & 38.9 \\
\hline
\end{tabular}

not observe significant differences in handgrip strength when comparing elite and non-elite judo players. On the other hand, Gutierrez-Sánchez et al. [11] indicated there is no basis to consider hand-grip strength as possible predictor of Judo performance.

When handgrip strength is measured with a hand dynamometer, the subject produces force with all fingers (i.e., performs a power grip task). However, different instruments and methods are recommended. Most manual grips can be divided into precision and power grips $[4,6]$. During the precision grip task, the subjects apply the tips of the thumb and fingers for the manipulation of small objects. During the power grip task, subjects flex all digits in palmar opposition around an object [6].

Dimensional and anatomical features of the human hand, such as the size and shape, and the texture of the object also influence grip formation and grip strength [12-14]. In some sport activities, such as rock climbing, the hands are used as tools because many external forces affect the fingers during exercising [2]. In sport games like handball and basketball, both handgrip strength and hand anthropometry are important for finger control and accuracy in different shots [15].

In judo many forces affect the fingers during gripping on the judogi, the ability to develop a strong grip and maintain it during a judo match has become an important element for judo athletes [5]. This may work more efficiently when the fingers and hand surface parameters are longer and when the fingers are stronger (which likely yields better handgrip strength). Recently, Fallahi and Jadidian [16] showed that handgrip strength and some of the hand dimensions may be different in athletes who have handgrip movements with an object or opponent in comparison to non-athletes. Also, there was a significant positive correlation between handgrip strength and most of the hand dimensions in grip athletes. In addition, some of the hand dimensions) in athletes may be good predictors of handgrip strength. It seems that the differences of these parameters in judo athletes have not been confirmed yet, and the information about these parameters is scarce.

The aim of this study was the influence of hand anthropometric parameters in handgrip strength and sport achievement.

\section{Material and Methods}

\section{Subjects}

Fifty four judokas aged $22 \pm 2.83$ (mean \pm SD) years participants of the Inter-University Championship of Spain 2009 took part in this study. All subjects were healthy, and none of them was taking any medications at the time of the study. They did not experience any pain or disability in their upper extremities.

All subjects and parents were thoroughly informed of the purposes and content of the study, and written informed consent was obtained from the subjects and coaches before participation. The research was undertaken in compliance with the Helsinki Declaration. Competitors experience was similar ( $8.8 \pm 3.77$ years). The subjects were divided into weight categories (50-66 kg, N=15; 67-81 kg, N=21; $+81 \mathrm{~kg}, \mathrm{~N}=18)$. The sport achievements were divided into results categories $(1-3 ; 4-6 ; 7-10 ;+11)$ (Table 1).

\section{Measurement of anthropometric parameters}

The body height (Martin metal anthropometer) and body mass (medical electronic scale; A \& D Instruments 


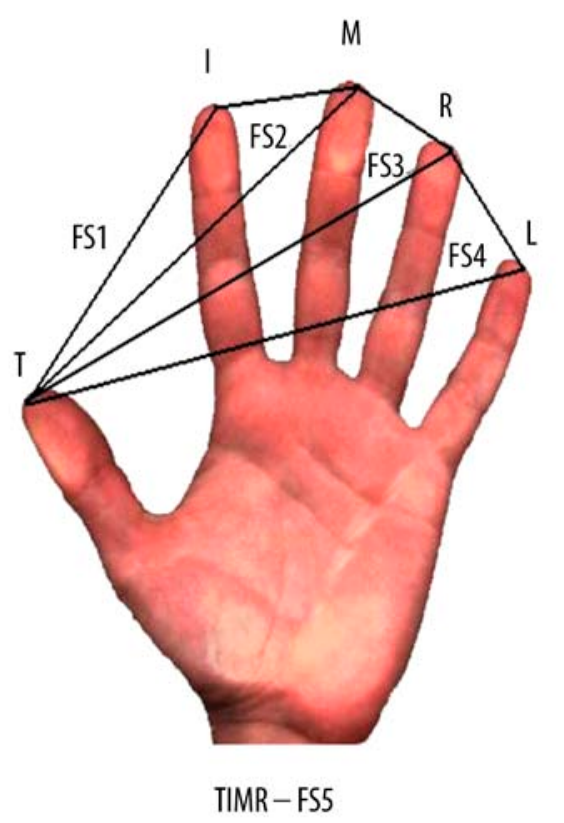

Figure 1. Measured finger spans of the dominant hand. $T$ - tip of thumb; I - tip of index finger; $M$ - tip of the middle finger; $R$ - tip of the ring finger; $L$ tip of the little finger; FS 1 - finger span $1 ;$ FS 2 finger span 2; FS 3 - finger span 3; FS 4 - finger span 4; FS 5 - finger span 5.

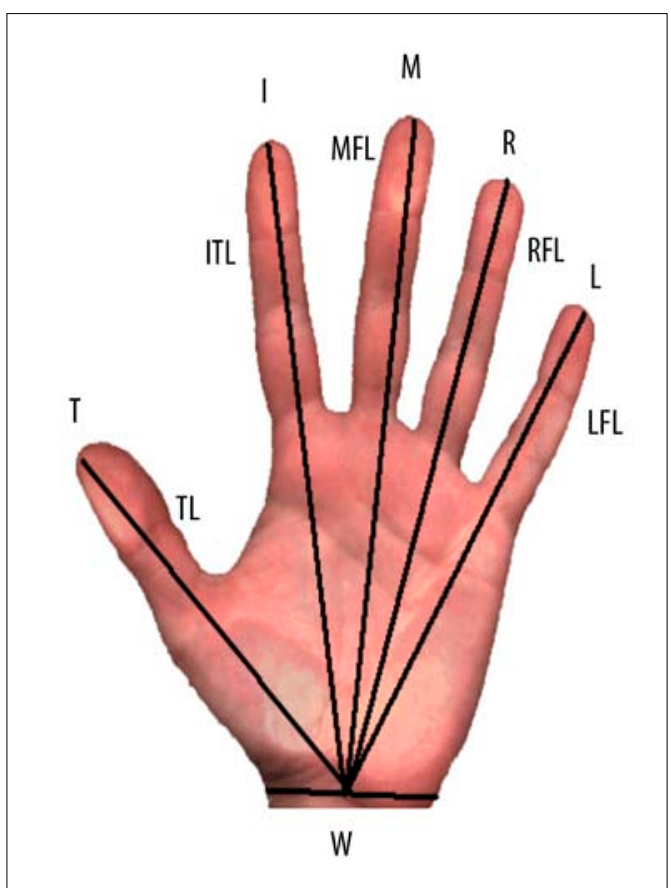

Figure 2. Measured finger lengths of the dominant hand. $T$ - tip of thumb; I - tip of index finger; $M$ - tip of the middle finger; $\mathrm{R}$ - tip of the ring finger; $\mathrm{L}$ - tip of the little finger; $\mathrm{W}$ - wrist; $\mathrm{TL}$ - thumb length; IFL - index finger length; MFL - middle finger length; RFL - ring finger length; $L F L$ - little finger length.

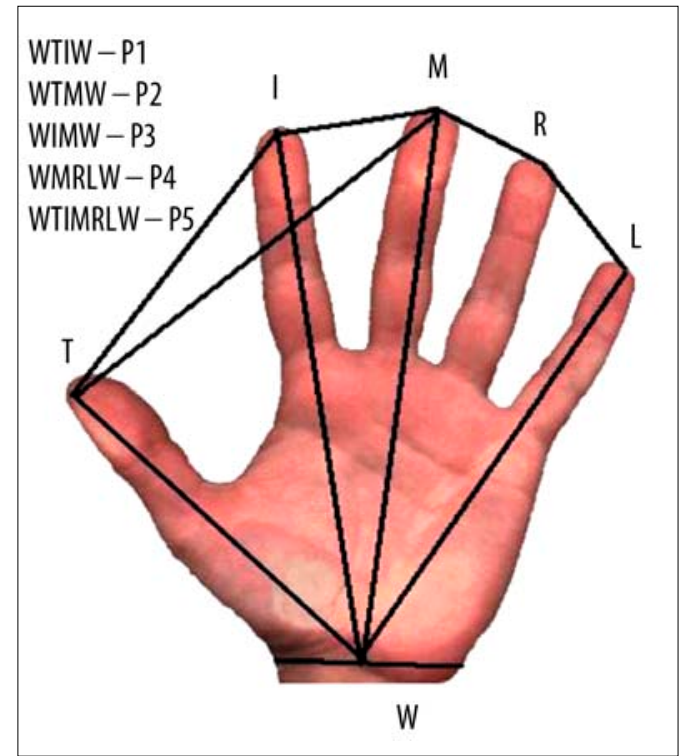

Figure 3. Measured finger perimeters of the dominant hand. T - tip of thumb; I - tip of index finger; $M$ tip of the middle finger; $R$ - tip of the ring finger; L - tip of the little finger; $W$ - wrist; WTIW - from the $W$ joint to the tip of $T$ to the tip of I finger and to the W joint; WTMW - from the W joint to the tip of $T$ to the tip of $M$ finger and to the $W$ joint; WIMW - from the W joint to the tip of I finger to the tip of $M$ finger and to the W joint; WMRLW from the $W$ joint to the tip of $M$ finger to the tip of $R$ finger to the tip of $L$ finger and the $W$ joint; WTIMRLW - from the $W$ joint to the tips of all fingers and to the $W$ joint.

Ltd., Abingdon, UK) of the subjects were measured to the nearest $0.1 \mathrm{~cm}$ and $0.05 \mathrm{~kg}$, respectively. Body mass index $\left(\mathrm{kg} \cdot \mathrm{m}^{-2}\right)$ was calculated. These measurements were taken in cooperation with the committee of judges (weighing commission).

We measured of specific anthropometric parameters of the hand according to Visnapuu and Jürimäe [15] criteria. The subjects were asked to be seated comfortably and were instructed to spread and stretch out the dominant hand and place it onto a piece of paper located on the table. The outline of the hand was drawn on the paper by one examiner for all subjects. The outlines were drawn with a thin marker that was placed perpendicularly onto the paper. The contour of the hand was drawn with maximal active voluntary adduction of thumb and other fingers. The outlines of the dominant hands of the subjects were used for measuring specific hand anthropometric parameters. Three groups of parameters were measured; finger spans, finger lengths, and some perimeters of the hand. The dimensions of the hand were measured with an accuracy of $0.1 \mathrm{~cm}$. The following parameters for span of the fingers were measured (Figure 1): from the tip of the thumb (T) to the tip of the index (I) finger (finger span $1[\mathrm{FSl}]$ ); from the tip of $\mathrm{T}$ to tip of the 
Table 2. Mean general parameters $(X \pm S D)$.

\begin{tabular}{|c|c|c|c|}
\hline \multirow{2}{*}{ Variable } & \multicolumn{3}{|c|}{ Weight groups (kg) } \\
\hline & $50-66(n=15)$ & $67-81(n=21)$ & $+81(n=18)$ \\
\hline Age (y) & $20.6 \pm 2.13^{* *}$ & $22 \pm 2.8$ & $23.17 \pm 2.87$ \\
\hline Height (cm) & $169.21 \pm 4.8^{*, * *}$ & $176.83 \pm 4.8^{* * *}$ & $184 \pm 4.65$ \\
\hline Body mass (kg) & $62.1 \pm 2.94^{*, * *}$ & $74.6 \pm 4.25^{* * *}$ & $94.77 \pm 7.92$ \\
\hline $\operatorname{BMI}\left(\mathrm{kg} \cdot \mathrm{m}^{-2}\right)$ & $21.70 \pm 1.29^{* * * *}$ & $23.87 \pm 1.42^{* * *}$ & $28.03 \pm 2.52$ \\
\hline Body span (cm) & $172.63 \pm 6.39^{*, * *}$ & $181.19 \pm 5.29 * * *$ & $186.69 \pm 6.63$ \\
\hline Training (y) & $6.67 \pm 4.41$ & $8.02 \pm 5.78$ & $6.89 \pm 5.06$ \\
\hline Competition (y) & $8.73 \pm 2.86$ & $8.33 \pm 4.01$ & $9.39 \pm 4.24$ \\
\hline Handgrip strength (kg) & $44.85 \pm 6.63^{*, * *}$ & $50.12 \pm 7.87$ & $54.15 \pm 7.16$ \\
\hline
\end{tabular}

Differences at $\mathrm{p}<0.05 ;{ }^{*}$ differences $50-66$ vs. 67-81; ** differences $50-66$ vs. $+81 ; * * *$ differences $67-81$ vs. +81 .

Table 3. Mean specific hand anthropometric parameters in centimeters $(X \pm S D)$.

\begin{tabular}{|c|c|c|c|}
\hline \multirow{2}{*}{ Variable } & \multicolumn{3}{|c|}{ Weight groups (kg) } \\
\hline & $50-66(n=15)$ & $67-81(n=21)$ & $+81(n=18)$ \\
\hline FS1 & $10.16 \pm 1.37$ & $10.22 \pm 0.95$ & $10.84 \pm 1.008$ \\
\hline FS2 & $13.79 \pm 1.43$ & $14.20 \pm 1.09$ & $14.43 \pm 1.14$ \\
\hline FS3 & $15.55 \pm 1.35$ & $16.12 \pm 1.38$ & $16.36 \pm 1.37$ \\
\hline FS4 & $17.84 \pm 1.54$ & $18.14 \pm 1.35$ & $18.44 \pm 1.14$ \\
\hline FS5 & $23.64 \pm 2.35$ & $24.31 \pm 1.82$ & $24.61 \pm 1.54$ \\
\hline $\mathrm{TL}$ & $12.81 \pm 0.79^{* * * *}$ & $13.53 \pm 0.71$ & $13.97 \pm 0.79$ \\
\hline IFL & $17.29 \pm 0.75^{*, * *}$ & $18.38 \pm 0.78$ & $18.66 \pm 0.85$ \\
\hline MFL & $18.08 \pm 0.66^{* * * *}$ & $19.26 \pm 0.81$ & $19.51 \pm 0.79$ \\
\hline RFL & $17.33 \pm 0.69^{* * * *}$ & $18.16 \pm 0.85$ & $18.4 \pm 0.77$ \\
\hline LFL & $15.28 \pm 0.70^{* * * *}$ & $15.97 \pm 0.72$ & $15.99 \pm 0.69$ \\
\hline P1 & $40.26 \pm 2.04^{* *}$ & $41.56 \pm 3.39^{* * *}$ & $43.49 \pm 2.09$ \\
\hline P2 & $44.69 \pm 1.78^{* * * *}$ & $46.99 \pm 1.94$ & $47.92 \pm 2.19$ \\
\hline P3 & $39.77 \pm 1.34^{*, * *}$ & $42.41 \pm 1.74$ & $42.41 \pm 1.85$ \\
\hline P4 & $42.31 \pm 1.13^{* * * *}$ & $44.51 \pm 1.77$ & $45.03 \pm 1.91$ \\
\hline P5 & $51.61 \pm 2.35^{*, * *}$ & $53.81 \pm 2.19$ & $54.04 \pm 3.77$ \\
\hline
\end{tabular}

Differences at $\mathrm{p}<0.05 ;{ }^{*}$ differences $50-66$ vs. $67-81 ;{ }^{* *}$ differences $50-66$ vs. $+81 ;{ }^{* * *}$ differences $67-81$ vs. +81 .

middle (M) finger (finger span 2 [FS2]); from the tip of $\mathrm{T}$ to the tip of the ring (R) finger (finger span 3 [FS3]); from the tip of $\mathrm{T}$ to the tip of the little (L) finger (finger span 4 [FS4]); and from the tip of T to the tip of each finger (finger span 5 [FS5]). Finger lengths were measured between the wrist ([W] proximal starting point at the hand length measurement) joint and the tip of the fingers (Figure 2): length from $\mathrm{W}$ joint to the tip of $\mathrm{T}$ (thumb length [TL]); length from $\mathrm{W}$ joint to the tip of I finger (index finger length [IFL]), length from $\mathrm{W}$ joint to the tip of $\mathrm{M}$ finger (middle finger length [MFL]); length from $\mathrm{W}$ joint to the tip of $\mathrm{R}$ finger (ring finger length
[RFL]); and the length from $\mathrm{W}$ joint to the tip of $\mathrm{L}$ finger (little finger length [LFL]). The following perimeters of the hand were measured (Figure 3): from the $\mathrm{W}$ joint (WTIW, P1); from the W joint (WTMW, P2); from the $\mathrm{W}$ joint to the tip of I finger to the tip of $\mathrm{M}$ finger and to the $\mathrm{W}$ joint (WIMW, P3); from the $\mathrm{W}$ joint to the tip of $\mathrm{M}$ finger to the tip of $\mathrm{R}$ finger to the tip of $\mathrm{L}$ finger and to the W joint (WMRLW, P4); from the W joint to the tips of all fingers and to the W joint (WTIMRLW, P5). In all subjects the hand anthropometry was repeated with a 1-hour interval for 2 times to calculate the reliability of measurement (intraclass correlations [ICCs]). 
Table 4. Relationships between handgrip strength and hand-specific anthropometric parameters.

\begin{tabular}{|c|c|c|c|c|}
\hline & $\begin{array}{l}\text { Body mass } \\
(\mathbf{k g})\end{array}$ & $\begin{array}{l}\text { Body height } \\
(\mathrm{cm})\end{array}$ & $\begin{array}{c}\text { BMI } \\
\left(\mathbf{k g} \cdot \mathbf{m}^{-2}\right)\end{array}$ & $\begin{array}{l}\text { Handgrip strength } \\
\qquad(\mathbf{k g})\end{array}$ \\
\hline Body mass & & $0.772^{* *}$ & $0.914^{* *}$ & $0.480^{* *}$ \\
\hline Body height & $0.772^{* *}$ & & $0.453^{* *}$ & $0.520^{* *}$ \\
\hline BMI & $0.914^{* *}$ & $0.453^{* *}$ & & $0.356^{* *}$ \\
\hline Handgrip strength & $0.480^{* *}$ & $0.520^{* *}$ & $0.356^{* *}$ & \\
\hline FS1 & $0.274^{*}$ & 0.242 & 0.233 & 0.001 \\
\hline FS2 & 0.219 & 0.178 & 0.197 & -0.046 \\
\hline FS3 & 0.207 & 0.197 & 0.171 & 0.001 \\
\hline FS4 & 0.125 & 0.129 & 0.102 & 0.009 \\
\hline FS5 & 0.176 & 0.146 & 0.163 & 0.034 \\
\hline $\mathrm{TL}$ & $0.516^{* *}$ & $0.633^{* *}$ & $0.329 *$ & $0.448^{* *}$ \\
\hline IFL & $0.540^{* *}$ & $0.730^{* *}$ & $0.303^{*}$ & $0.507^{* *}$ \\
\hline MFL & $0.550^{* *}$ & $0.745^{* *}$ & $0.309^{*}$ & $0.505^{* *}$ \\
\hline RFL & $0.451^{* *}$ & $0.696^{* *}$ & 0.196 & $0.462^{* *}$ \\
\hline LFL & $0.303^{*}$ & $0.601^{* *}$ & 0.050 & $0.404^{* *}$ \\
\hline P1 & $0.446^{* *}$ & $0.486^{* *}$ & $0.319^{*}$ & 0.145 \\
\hline P2 & $0.531^{* *}$ & $0.633^{* *}$ & $0.351^{* *}$ & $0.350^{* *}$ \\
\hline P3 & $0.475^{* *}$ & $0.650^{* *}$ & 0.263 & $0.441^{* *}$ \\
\hline P4 & $0.454^{* *}$ & $0.656^{* *}$ & 0.236 & $0.490^{* *}$ \\
\hline P5 & $0.301^{*}$ & $0.401^{* *}$ & 0.177 & $0.368^{* *}$ \\
\hline
\end{tabular}

Pearson's coefficient of correlation $(r){ }^{*} p<0.05 ;{ }^{* *} p<0.01$.

\section{Measurement of handgrip strength}

The maximal handgrip strength of the dominant hand was measured with a hand dynamometer (GRIP-D TKK 5401, Takei Scientific Instruments CO). Hand dominance was determined by asking the subject which hand was used to hold a pencil and to throw a ball [17]. The subjects were standing comfortably with the shoulder adducted. The dynamometer, which had been previously adjusted to the size of their hand, was held freely without support; it was not touching the subject's trunk. The position of the hand remained constant, with a downward direction. The palm did not flex on the wrist joint. The subjects were required to exert maximal strength on the dynamometer (maximal voluntary contraction) for 5 seconds. All subjects performed 3 trials, and the best performance was used in both hands.

\section{Statistical analysis}

Standard statistical methods were used to calculate mean and SD. A Fisher's least significant differences test was used to determine the differences between weight groups. Pearson correlation coefficients were used to determine the relationships between independent variables. As handgrip strength highly correlated with body mass, the partial correlation analyses were used to calculate the relationships between handgrip strength and hand anthropometrical parameters where body mass was eliminated. The effects of general body and specific hand anthropometric parameters (finger spans, finger lengths, and perimeters) on the handgrip strength and on sport achievements were analyzed using stepwise multiple regression analysis. Reliability of hand anthropometrical parameters was assessed using 2-way average-measures ICCs, based on a subset of ten 50-66 kg, ten 6781 , and ten +81 judoists. For all tests, the significance level was set at $\mathrm{p}<0.05$. The analyses were done using SPSS 15.0 (SPSS Inc. Chicago, IL).

\section{Results}

In Tables 2 and 3, the mean general body, experience information, and specific hand anthropometric parameters 
Table 5. Relationships between handgrip strength and hand-specific anthropometric parameters.

\begin{tabular}{|c|c|c|c|}
\hline \multirow{2}{*}{ Variable } & \multicolumn{3}{|c|}{ Handgrip strength of the dominant hand } \\
\hline & $50-66 \mathrm{~kg}(\mathrm{n}=15)$ & $67-81 \mathrm{~kg}(\mathrm{n}=21)$ & $+81 \mathrm{~kg}(\mathrm{n}=18)$ \\
\hline FS1 & -0.031 & -0.133 & -0.217 \\
\hline FS2 & 0.061 & -0.258 & -0.264 \\
\hline FS3 & 0.141 & -0.298 & -0.085 \\
\hline FS4 & 0.165 & -0.372 & 0.109 \\
\hline FS5 & 0.036 & -0.351 & 0.231 \\
\hline $\mathrm{TL}$ & 0.187 & 0.395 & 0.217 \\
\hline IFL & 0.113 & $0.496^{*}$ & 0.331 \\
\hline MFL & 0.073 & $0.456^{*}$ & 0.353 \\
\hline RFL & 0.142 & 0.390 & 0.329 \\
\hline LFL & 0.314 & 0.379 & 0.157 \\
\hline P1 & 0.093 & -0.200 & 0.096 \\
\hline P2 & 0.158 & 0.189 & 0.069 \\
\hline P3 & 0.233 & 0.340 & 0.252 \\
\hline P4 & 0.241 & 0.191 & $0.554^{*}$ \\
\hline P5 & 0.216 & -0.039 & $0.540^{*}$ \\
\hline
\end{tabular}

Pearson's coefficient of correlation $(r) * p<0.05$.

are presented. Body height, BMI, body span, and body mass had increased significantly by the weight groups.

Weight groups showed no significant differences in finger span parameters. All finger lengths increased significantly at the weight groups of 67-81 and +81 , compared with 50-66 $(\mathrm{p}<0.05)$. There were significant differences in all hand parameters (P1-P5) of weight groups at the weight of $67-81$ and +81 compared with 50-66, and in perimeter $\mathrm{Pl}$ at the weight group 67-81 compared to the weight group of $+81(p<0.05)$. The reliability of the hand anthropometrical parameters (finger spans, finger lengths, and perimeters) in both groups was very high $(r>0.90)$.

Table 2 presents the mean handgrip strength measures for the dominant hand with the advancement of weight. From the total of 54 participants studied, the right hand was dominant for $100 \%$. There were significant differences in maximal handgrip strength at the weight group of 50-66 kg compared with that observed in other weight groups $(\mathrm{p}<0.05)$.

There were significant relationships between maximal handgrip strength of the dominant hand and general anthropometric variables $(\mathrm{r}=0.35-0.52)$ in all subjects (Table 4 ), but this was not the case with specific hand dimensions.
However, by weight categories, maximal handgrip strength of the dominant hand was not significant with regard to $50-66 \mathrm{~kg}$, and in the case of the 67-81 and $+81 \mathrm{~kg}$, the relationship was lower but significant in IFL, MFL and P4, P5 respectively (Table 5).

The relationship between sport achievement and hand anthropometric parameters was not significant with regard to 50-66 and 67-81 weight categories, but in the case of the +81 , the relationship was low but significant in TL, r=0.525; IFL, $r=0.522$; MFL, $r=0.479 ; \mathrm{P} 4$, $\mathrm{r}=0.470$ and highly significant in $\mathrm{P} 3, \mathrm{r}=0.602$.

The results of the stepwise multiple regression analysis from the hand anthropometric parameters (independent parameters were all measured finger spans, finger lengths, or perimeters separately), handgrip strength was dependent on IFL and Pl $\left(33.5 \%, \mathrm{R}^{2} \times 100\right)$ in $67-81 \mathrm{~kg}$ and in $+81 \mathrm{~kg}$ from P4 (26.4\%); sport achievement was dependent on P3 and FSI (44.4\%) in $+81 \mathrm{~kg}$.

\section{Discussion}

In many sports, the characteristics of the hand are of major importance. In sports involving grasping an object such as basketball and handball, players with bigger hands and longer fingers have better accuracy of the shot [16]. In other grip sports like rock climbing, wrestling or judo, hand 
strength plays a major role [3,18] and hand morphology has been proposed as one of its main contributors [15].

In the judo combat, there are constant dynamic changes and strength, coordination and aerobic-anaerobic endurance are crucial abilities for judo performance [6]. Grapping first the opponent means taking the initiative, since this technical action allows the judoka to attack, defend and counter-attack. During the grip contest (when both athletes have grasped each other's judogui), movements can be done in a span of four to six directions with a single grasp, indicating the importance and relevance of the grip phase of the combat to the final outcome. This explains why the dispute for grip comprises the largest portion of the match (about 50\%), far longer than breaks $(20 \%)$, groundwork $(20 \%)$, preparation (10\%) and technique execution (5\%) [19]. Furthermore, expert judokas considerably spend more time in grip contest (trying to grip the opponent without being gripped) and less time actually gripping compared to beginners and intermediate level judokas [9], highlighting hand grip ability as a key performance indicator to take into account when aiming to improve judo's performance.

Both general anthropometric (body weight, body height, body mass index) and hand measurements (finger spans, finger lengths, hand perimeters) have been related to handgrip strength [13,16,20-30], although the results are not conclusive. In our study, all three general anthropometric measurements were positively correlated $(r=0.35-0.42)$ with handgrip strength, being body height the best correlated variable. Jürimäe et al. [25] also found that body height was the most important general anthropometric measurement, which was able to explain up to $76.1 \%$ of the handgrip strength in prepubertal children. Furthermore, Luna-Heredia et al. [22], stated that body height has a very good correlation with handgrip strength because it is the factor more closely related to lean body mass, and Serrano et al. [23] indicates that greater body height implies the development of long bones such as the ulna and radius, lengthening the arm muscle fibres and thus developing new contractile units between the tendon and the muscle, facilitating the grip strength gain as a consequence.

Participants in this study were divided into different weight categories because Judo is a weight-classified sport and significant differences in handgrip strength have been found among weight categories [11]. Therefore, it was interesting to find out whether these differences also existed in the general and hand anthropometric measurements of the judokas.

In the present study, maximal handgrip strength was significantly different only in the $50-66 \mathrm{~kg}$ weight group, accompanied by significant differences in all finger lengths -TL, IFL, MFL, RFL, LFL - and hand perimeters - P1, P2, P3, P4, P5 - for the very same group. It is noteworthy that all finger lengths and hand perimeters were significantly different only in the group that showed different maximal handgrip strength. Fallahi and Jadidian [16] also found significant differences in finger lengths and hand perimeters between handgrip-related athletes and non-athletes, which indicates that these variables may have a positive effect on handgrip strength.

All finger lengths and hand perimeters but Pl positively correlated with handgrip strength for the whole group, but the best correlations between hand specific parameters and handgrip strength were IFL, MFL and P4. These results are in agreement with other studies, such as Jürimäe et al. [25], who found that the most important hand specific variables that influence handgrip strength in prepubertal children were MFL and P4 as well. They concluded that MFL was very similar to the midstylion-dactylion length that was selected as their best variable characterising handgrip strength among the hand length measurements, and MFL is included in the measurement of $\mathrm{P} 4$, thus both are related and seem to play a major role in handgrip strength.

Similarly, Fallahi and Jadidian [16] found that FS5 and P5 in athletes, P4 in non-athletes and IFL in both groups were the best predictors for handgrip strength. However, in our study, no finger span had a significant correlation with handgrip strength. Although Jürimäe et al. [25] found FS4 as a relevant variable correlated to handgrip strength, they concluded that its influence was relatively low compared with length and perimeter variables. Also, Visnapuu and Jürimäe [15] suggested that the effect of finger length and perimeters on handgrip strength is more than that of finger spans so that finger spans have a small influence on handgrip strength. In the same line, Nevill and Holder [31] stated that the larger the size of the hand the greater the handgrip strength and Nicolay and Walker [20] indicated that forearm and hand measurements (wrist circumference, palm width and palm length) serve as better predictors of grip strength than the more commonly recorded quantities of height and weight and pointed palm width as the univariate measurement most tightly associated with maximum voluntary force. Finally, Hager-Ross and Rösblad [30] found a strong correlation between hand length and peak grip strength in children aged 4-16 years. These studies tend to indicate that there is a relationship between hand anthropometrics and grip strength, although no conclusive agreement of the precise role of the aforementioned variables exists.

Regarding sport achievement, no relationship was found between the hand measurements and sport achievement 
for the $50-66 \mathrm{~kg}$ and $67-81 \mathrm{~kg}$, and only a few handspecific measurements for the $+81 \mathrm{~kg}$ weight group were significantly low -TL, IFL, MFL, P4 - and high - P3 - correlated. The best prediction of sport achievement variance was $44.4 \%$, characterized by FS1 and P3. In a previous study carried out by Gutierrez-Sánchez et al. [11], no relationship was found between grip strength and Judo performance in boys in the different weight groups either, although they found significant differences in their female judokas. These results suggest that hand characteristics (anthropometry and strength) may not be good predictors of sport achievement in Judo.

\section{Conclusions}

The main conclusion of our study is that the handgrip strength is mostly dependent on the basic (body height) and hand-specific (IFL, MFL, and P4) anthropometric parameters in judokas. These results are very interesting because athletes with specific hand dimensions may have biomechanical advantages regarding handgrip strength and this information can be valuable for coaching and talent identification in Judo.

Sport achievement was related to hand perimeter (P3), but its variability was weakly explained and thus handspecific measurements may not be good predictors for judo performance. In summary, this study provides more evidence of the influence of some general and hand-specific variables on handgrip strength and performance in Judo, although the precise role these anthropometric variables play has not yet been conclusively determined.

\section{Acknowledegments}

Thanks are due to the athletes who took part in this study.

\section{References:}

1. Maughan RJ, Abel RW, Watson JS, Weir J: Forearm composition and muscle function in trained and untrained limbs. Clin Physiol, 1986; 6: 389-96

2. Quaine F, Vigouroux L, Martin L: Effect of simulated rock climbing finger postures on force sharing among the fingers. Clin Biomech, 2003; 18: 385-88

3. Watts PB, Joubert LM, Lish AK et al: Anthropometry of young competitive sport rock climbers. Br J Sports Med, 2003; 37: 420-24

4. Blackwell JR, Kormatz KW, Heath EM: Effect of grip span on maximal grip force and fatigue of flexor digitorum superficialis. Appl Ergon, 1999; 30: $401-5$

5. Franchini E, Del Vecchio FB, Matsushigue KA, Artioli GG: Physiological profiles of elite judo athletes. Sports Med, 2011; 41: 147-66

6. Krstulovic S, Zuvela F, Katic R: Biomotor systems in elite junior judoists. Coll Antropol, 2006; 30(4): 845-5 I

7. Aruga S, Nakanishi H, Yamashita Y et al: A study on the training method for improving judo players' kumite strength - on the judogi chin-up method. Tokai J Sports Med Sci, 2006; 18: 44-53 [in Japanese, English abstract]

8. Franchini E, Nunes AV, Moraes JM, Del Vecchio FB: Physical fitness and anthropometrical profile of the Brazilian male judo team. J Physiol Anthrop, 2007; 226: 59-67

9. Calmet M, Miarka B, Franchini E: Modeling of grasps in judo contests. Int J Perf Analysis Sport, 2010; 10: 229-40

10. Franchini E, Takito MY, Kiss MAPDM, Sterkowicz S: Physical fitness and anthropometrical differences between elite and non-elite judo players. Biol Sport, 2005; 22: 315-28

11. Gutierrez-Sánchez A, Soria-Domínguez A, PérezTurpin JA et al: Importance of hand-grip strength as an indicator for predicting the results of competitions of young judokas. Arch Budo, 2011; 7(3): 167-72
12. Firrell JC, Crain GM: Which setting of the dynamometer provides maximal grip strength? J Hand Surg, 1996; 21: 397-401

13. Fraser A, Vallow J, Preston A, Cooper C: Predicting "normal" grip strength for rheumatoid arthritis patients. Rheumatology, 1999; 33: 521-28

14. Nag A, Nag PK, Desai H: Hand anthropometry of Indian women. Ind J Med Res, 2003; 1 17: 260-69

15. Visnapuu M, Jürimäe T: Handgrip strength and hand dimensions in young handball and basketball players. J Strength Cond Res, 2007; 21 (3): 923-29

16. Fallahi AA, Jadidian AA: The effect of hand dimensions, hand shape and some anthropometric characteristics on handgrip strength in male grip athletes and non-athletes. J Hum Kinet, 201 1; 29: 151-59

17. Ager CL, Olivett BL, Johnson CL: Grasp and pinch strength in children 5 to 12 years old. Am J Occup Ther, 1984; 38: 107-13

18. Leyk D,Gorges W, Ridder D et al: Hand-grip strength of young men, women and highly trained female athletes. Eur J Appl Physiol, 2007; 99(4): 415-21

19. Marcon G, Franchini E, Jardim JB, Barros Neto TL: Structural Analysis of Action and Time in Sports: Judo. Journal of Quantitative Analysis in Sports, 2010; 6(4): 10

20. Nicolay CW, Walker AL: Grip strength and endurance: Influences of anthropometric variation, hand dominance, and gender. Int J Ind Ergon, 2005; 35 605-18

21. Gandhi M, Koley S, Sandhu JS: Association between Anthropometric Characteristics and Physical Strength in School Going Children of Amritsar. Anthropologist, 2010; 12(1): 35-39

22. Luna-Heredia E, Martin-Peña G, Ruiz-Galiana J: Handgrip dynamometry in healthy adults. Clin Nutr, 2005; 24: 250-58
23. Serrano MDM, Collazos JFR, Romero SM et al: Dinamometría en niños y jóvenes de entre 6 y 18 años: valores de referencia, asociación con tamaño y composición corporal. An Pediatr, 2009; 70(4): 340-48 [in Spanish]

24. Semproli S, Brasili P, Toselli S et al: The influence of anthropometric characteristics to the handgrip and pinch strength in 6-10 year old children. Anthrop, 2007; 65(3): 293-302

25. Jürimäe T, Hurbo T, Jürimäe J: Relationship of handgrip strength with anthropometric and body composition variables in prepubertal children. Homo, 2009; 60: 225-38

26. Koley S, Gandhi M, Singh AP: An association of hand grip strength with height, weight and BMI in boys and girls aged 6-25 years of Amritsar. The Internet Journal of Biological Anthropology, 2008; 2(1)

27. Koley S, Singh J, Sandhu JS: Anthropometric and physiological characteristics on Indian inter-university volleyball players. J Hum Sport Exerc, 2010; 5(3): 389-99

28. Nevill AM, Holder RL: Modelling handgrip strength in the presence of confounding variables: results from the Allied Dunbar National Fitness Survey. Ergonomics, 2000; 43(10): 1547-58

29. Bowen IJ, Mendoza de Sosa D: Valores de la fuerza de la mano en adultos sanos. Boletín Médico de Postgrado, 2001; 17(2): 1-13 [in Spanish]

30. Häger-Ross C, Rösblad B: Norms for grip strength in children aged 4-16 years. Acta Paediatr, 2002; 91: 617-25

31. Nevill AM, Holder RL: Modelling handgrip strength in the presence of confounding variables: results from the Allied Dunbar National Fitness Survey, 2002. In: Reilly T, Greeves J (eds.), Advances in Sport, Leisure and Ergonomics. Routledge, London, 291-302

Cite this article as: Cortell-Tormo JM, Perez-Turpin JA, Lucas-Cuevas ÁG et al.: Handgrip strength and hand dimensions in high-level inter-university judoists. Arch Budo, 2013; 1: 21-28. 